\section{Commentary: Evolution of pediatric living-donor lung transplant: Adaptation to unique environment}

\author{
Iki Adachi, MD, and Jeffrey Heinle, MD
}

In this issue of the Journal, Oto and colleagues ${ }^{1}$ described their experience in 3 infants with end-stage lung disease due to idiopathic pulmonary fibrosis who had undergone living-donor lung transplant using the splitting adult lower lobe technique. The technical detail of the procedure is concisely described, supplemented with a well-edited surgical video. The lower lobe from a single adult donor was split into the superior and basal segments in vivo to perform sequential bilateral implantation. There was mortality 3 months postimplant due to infection in a 1-year-old patient, whereas the other 2 patients ( 2 and 4 years old) are alive at 29 and 68 months. The latter patient is now being considered for repeat transplant due to pulmonary hypertension of unclear etiology, which is speculated as a result of the patient's outgrowth relative to the lung graft size. Given the critical condition, however, none of these patients would have survived without the novel transplant procedure. The authors should be congratulated on the remarkable clinical achievement as well as their continuous effort to lead the field of living-donor lung transplant in the pediatric population.

The obvious downside of the described novel technique as opposed to the standard middle lobe technique ${ }^{2}$ is the need for an additional splitting maneuver, which may increase the risk of bleeding, air leak, and infection. In

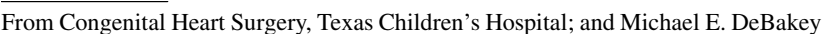
Department of Surgery, Baylor College of Medicine, Houston, Tex. Disclosures: The authors reported no conflicts of interest.

The Journal policy requires editors and reviewers to disclose conflicts of interest and to decline handling or reviewing manuscripts for which they may have a conflict of interest. The editors and reviewers of this article have no conflicts of interest.

Received for publication June 29, 2020; revisions received June 29, 2020; accepted for publication July 2, 2020; available ahead of print July 9, 2020.

Address for reprints: Iki Adachi, MD, Mechanical Circulatory Support, Congenital Heart Surgery, Texas Children's Hospital, 6651 Main St, Houston, TX 77030 (E-mail: iadachi@bcm.edu).

JTCVS Techniques 2020;3:317-8

2666-2507

Copyright (C) 2020 The Authors. Published by Elsevier Inc. on behalf of The American Association for Thoracic Surgery. This is an open access article under the CC BY-NCND license (http://creativecommons.org/licenses/by-nc-nd/4.0/).

https://doi.org/10.1016/j.xjtc.2020.07.001
}

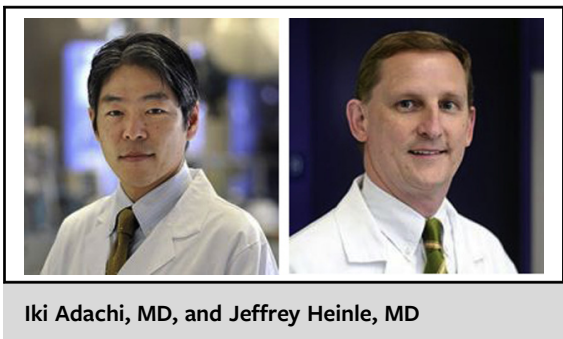

CENTRAL MESSAGE

Pediatric living-donor lung transplant, which has been abandoned in most countries such as the United States, continues to evolve in Japan as an adaptive response to the unique environment.

addition, compared with the standard brain-death donor transplant, the need for pulmonary venous anastomosis "without atrial cuff" poses a technical challenge and may negatively impact the patency of the anastomosis in the long term. In general, creation of a suture line on the pulmonary vein itself carries a substantial risk of developing stenosis at a later date. This is primarily why surgical procedures involving "no suture line" on the pulmonary vein, the so-called sutureless repair, ${ }^{3}$ are gaining widespread acceptance in the repair of total anomalous pulmonary venous return. In the aforementioned patient who developed pulmonary hypertension, the pulmonary arterial wedge pressure was elevated bilaterally (right and left, 14 and $16 \mathrm{~mm} \mathrm{Hg}$, respectively). If the patient had a normally functioning heart (most likely), there would be no reason for the left atrial pressure to be so elevated. The observed elevation of pulmonary arterial wedge pressure may represent, therefore, presence of subclinical obstruction in the pulmonary venous drainage, which could have led to pulmonary hypertension over time, as opposed to the authors' speculation upon the patient outgrowth. Simultaneous measurement of left atrial and wedge pressure would provide a clear answer to this important question.

A series of techniques for pediatric living-donor lung transplant have evolved over years under the peculiar circumstances in the authors' nation, Japan, where there is an extreme limitation in brain-death donor organ availability associated with their strict organ donation law. It is interesting to see the operation (ie, pediatric living-donor lung transplant), which has been abandoned in most countries 
such as United States, continues to evolve in the other side of the planet as an adaptive response to the unique environment. Charles Darwin's theory of evolution appears to be applied not only to biology but surgery. The most important lesson we learned from this report as surgeons who perform pediatric brain-death donor lung transplant is how the authors conduct the procedure in an elegantly controlled fashion, as demonstrated in the video. This is in stark contrast to the brain-death lung transplant, which is inherently associated with various uncertainties, including timing and organ quality. One may say that conduct of living-donor transplant rather than brain-death transplant transforms an unpredictable procedure into a more controlled operation, which is likely a part of the reason why the authors' institutional outcomes are so remarkable. The report Oto and associates present may elicit a debate on the potential role of pediatric living-donor lung transplant in the current era.

\section{References}

1. Oto T, Hikasa Y, Hagiyama A, Kobayashi M. Bilateral segmental lung transplantation for children: transplantation using split adult living-donor lower lobe. J Thorac Cardiovasc Surg Tech. 2020;3:311-4.

2. Oto T, Miyoshi K, Sugimoto S, Yamane M. Living related donor middle lobe lung transplant in a pediatric patient. J Thorac Cardiovasc Surg. 2015;149:42-4.

3. Najm HK, Caldarone CA, Smallhorn J, Coles JG. A sutureless technique for the relief of pulmonary vein stenosis with the use of in situ pericardium. J Thorac Cardiovasc Surg. 1998;115:468-70. 